\section{Influence of Costus speciosus (Koen.) Sm. Rhizome Extracts on Biochemical Parameters in Streptozotocin Induced Diabetic Rats}

\author{
Pitchai Daisy, ${ }^{*}, a$ James Eliza, ${ }^{a}$ \\ and Savarimuthu Ignacimuthu ${ }^{b}$
}

${ }^{a}$ Department of Biotechnology, Holy Cross College, Truchirappali-620002, Tamil Nadu, India and ${ }^{b}$ Division of Ethnopharmacology, Entomology Research Insititute, Loyola College, Chennai-600034, Tamil Nadu, India.

(Received July 3, 2008; Accepted July 23, 2008)

Diabetes affects about $4 \%$ of the global population and management of diabetes without any side effects is still a challenge to the medical system. The present study investigated the possible protective effects of Costus speciosus (Koen.) sm. (C. speciosus) rhizome extracts on biochemical parameters in streptozotocin (STZ)-induced male diabetic Wistar rats. STZ treatment $(50 \mathrm{mg} / \mathrm{kg}$, i.p.) caused a hyperglycemic state that led to various physiologic and biochemical alterations. Hexane, ethyl acetate, and methanol crude extracts administered at the dose of $250 \mathrm{mg} / \mathrm{kg}, 400 \mathrm{mg} / \mathrm{kg}$, and $400 \mathrm{mg} / \mathrm{kg}$, respectively, for 60 days to STZ-induced hypoglycemic and normoglycemic rats. The plasma glucose concentration was significantly $(p<0.05)$ decreased by all three extracts compared with controls. In addition, oral administration of hexane extract significantly decreased glycosylated hemoglobin $\left(\mathrm{HbA}_{1 \mathrm{c}}\right)$, serum total cholesterol, and triglyceride levels, urea, uric acid, and creatinine and at the same time markedly increased plasma insulin, tissue glycogen, serum protein, and highdensity lipoprotein (HDL) cholesterol levels. The hexane crude extract also restored the altered plasma enzymes aspartate aminotransferase (AST), alanine aminotransferase (ALT), alkaline phosphatase (ALP) and acid phosphatase (ACP) levels to near normal. Glibenclamide used as a reference drug $(0.6 \mathrm{mg} / \mathrm{kg}$ body weight) also produced a significant reduction in the blood glucose concentration in STZ-induced diabetic rats. In summary, the hexane crude extract was found to be more active in comparision with ethyl ac-

\footnotetext{
*To whom correspondence should be addressed: Department of Biotechnology, Holy Cross College, Trichy-620002, Tamil Nadu, India. Tel.: +91-431-2700637; Fax: +91-431-271331; E-mail: daisylesslie@yahoo.com
}

etate and methanol extracts. Thus this study shows that the $C$. speciosus hexane extract has antihyperglycemic and hypolipidemic activity, is able to ameliorate the diabetic state, and is probably a source of hypoglycemic compounds.

Key words_Costus speciosus (Koeing) and Smith, streptozotocin, biochemical alteration, hypoglycemia, hypolipidemia, hypoglycemic compound

\section{INTRODUCTION}

Diabetes mellitus is a chronic metabolic disorder affecting approximately $4 \%$ population worldwide and is expected to increase to $5.4 \%$ in $2025 .{ }^{1)}$ Epidemologic studies and clinical trials strongly support the notion that hyperglycemia is the main cause of complications such as coronary artery disease, cerebrovascular disease, renal failiure, blindness, limb amputation, neurological complications and premature death. ${ }^{2)}$ Type 2 diabetes results from the inability of the body to respond properly to the action of insulin produced by the pancreas. It is the most prevalent form of diabetes, accounting for around $90 \%$ of all diabetes cases. Before the discovery of insulin and other drugs for diabetes control, herbal medicines were the major form of treatment for diabetes and its complications. In addition to drugs classically used for the treatment of diabetes (insulin, sulfonylureas, biguanides, and thiazolidnediones), several species of plants have been described in the scientific and popular literature as having hypoglycemic activity. ${ }^{3-5)}$ Because of their perceived effectiveness, minimal side effects in clinical experience, and relatively low cost, herbal drugs are prescribed widely even when their biologically active compounds are unknown. ${ }^{6}$

At present there is growing interest in herbal remedies due to the side effects associated with the oral hypoglycemic agents for the treatment of diabetes mellitus. ${ }^{1)}$ Nearly 100 polysaccharides from plants have been reported to have hypoglycemic activity. Some botanical polysaccharides are considered as important bioactive components responsible for hypoglycemic effects. ${ }^{7}$ ) A number of plants have hypolipidemic effects. ${ }^{8)}$ However, there is little information on plants with both hypoglycemic and hypolipidemic effects. Costus speciosus (Koeing) and Smith (C. speciousus), spiral or wild ginger, belongs to the family Costaceae. C. speciosus 
rhizomes are an important source of diosogenin and are used in many human and veterinary medicines. C. speciosus alkaloids have been shown to possess anticholinesterase activity both in vitro and in vivo.9) An aqueous extract of $C$. speciosus showed significant hypoglycemic effects when it was administered orally with a simultaneous glucose load. ${ }^{10)}$

In the current literature there is no detailed study on the effects of different extracts of $C$. speciosus on the biochemical parameters and activity of enzymes abnormally altered due to diabetes mellitus. Therefore the present study aimed to assess the influence of the oral administration of $C$. speciosus rhizome extracts on the levels of biochemical parameters and activities of enzymes in streptozotocin (STZ)-induced diabetes rats.

\section{MATERIALS AND METHODS}

Plant Material $-C$. speciosus rhizomes were collected from Trinelveli district, Tamil Nadu, India. The species was identified and authenticated at the Department of Botany, Holy Cross College, Trichy, Tamil Nadu. The rhizomes were shadedried, cut into small pieces, and coarsely powdered. The coarse powder was used for extraction with various solvents.

Preparation of Crude Extracts - The various crude extracts of $C$. speciosus were prepared using the cold percolation method. The powder was dissolved in hexane, ethyl acetate, and methanol in a 1:3 ratio. Extracts were filtered and evaporated to dryness in a rotary evaporator to yield $1.5 \%$ hexane, $1.4 \%$ ethyl acetate, and $12.5 \%$ methanol extracts. A weighed portion of each extract was suspended in $0.5 \%$ aqueous carboxymethyl cellulose (CMC) solution in distilled water prior to oral administration to animals. Animals in the control group received only the vehicle $[5 \mathrm{ml} / \mathrm{kg}$ body weight (b.w.)]. Glibenclamide $(0.6 \mathrm{mg} / \mathrm{kg}$ b.w.) was used as the reference drug.

Experimental Animals - Male Wistar strain rats weighing about $200-250 \mathrm{~g}$ bred in the animal house, King Institute, Chennai, Tamil Nadu, India, were used for this study. The experimental protocol was approved by the Institutional Animal's Ethics Committee and by the regulatory body of the government (Regular No. 585/05/A/CPCSEA). All the animals were kept and maintained under laboratory conditions of temperature $\left(22 \pm 2^{\circ} \mathrm{C}\right)$, humidity
(45 $\pm 5 \%$ ), and $12 \mathrm{hr}$ day/12 hr night cycle and were allowed free access to food (standard pellet diet) and water ad. libitum. The animals were divided into 10 groups of 6 rats each.

Induction of Diabetes — Diabetes was induced in rats by the intraperitoneal injection of STZ at a dose of $50 \mathrm{mg} / \mathrm{kg}$ b.w. dissolved in $0.1 \mathrm{M}$ citrate buffer ( $\mathrm{pH} \mathrm{4.5)} \mathrm{in} \mathrm{a} \mathrm{volume} \mathrm{of} 1 \mathrm{ml} / \mathrm{kg}$ b.w. seven days after the injection, the blood glucose levels were measured. Each animal with a blood glucose concentration level greater than $250 \mathrm{mg} / \mathrm{dl}$ was considered to be diabetic and used in the experiments. Blood was collected by sinocular puncture.

Experimental Design — The body weight and fasting blood glucose levels of all the rats were determined before the start of the experiment, Rats were divided into the following groups: group 1, normoglycemic controls given vehicle $(0.5 \% \mathrm{CMC}$ $5 \mathrm{ml} / \mathrm{kg}$ ) alone; group 2, normoglycemic reference group given glibenclamide $0.6 \mathrm{mg} / \mathrm{kg}$; group 3 , normoglycemic group given hexane extract $250 \mathrm{mg} / \mathrm{kg}$; group 4, normoglycemic group given ethyl acetate extract $400 \mathrm{mg} / \mathrm{kg}$; group 5, normoglycemic group given methanol extract $400 \mathrm{mg} / \mathrm{kg}$; group 6 , diabetic controls given vehicle $(0.5 \%$ CMC $5 \mathrm{ml} / \mathrm{kg})$ alone; group 7, diabetic reference group given glibenclamide $0.6 \mathrm{mg} / \mathrm{kg}$; group 8 , diabetic group given hexane extract $250 \mathrm{mg} / \mathrm{kg}$; group 9, diabetic group given ethyl acetate extract $400 \mathrm{mg} / \mathrm{kg}$; and group 10, diabetic group given methanol extract $400 \mathrm{mg} / \mathrm{kg}$.

These 10 groups were given the agents for 60 days. At the end of 60 days, the rats were decapitated, blood was collected in heparinized tubes, and the plasma and serum were separated by centrifugation for the biochemical analysis. The liver and muscle were quickly removed, washed in ice-cold isotonic saline, and blotted individually on ash-free filter paper.

Biochemical Analysis — Blood samples were examined to determine plasma glucose, ${ }^{11)}$ protein, ${ }^{12)}$ glycosylated hemoglobin $\left(\mathrm{HbA}_{1 \mathrm{c}}\right),{ }^{13,14)}$ and plasma insulin using a radioimmunoassay kit (Pharmacia, Uppsala, Sweden) with a beta metric counter (Cornex, Dupnot, France). The serum concentrations of urea, uric acid, and creatinine were determined with a autoanalyzer using reagent kit obtained from Boehringer (Mannheim, Germany). Serum total cholesterol, triglycerides, and serum high-density lipoprotein (HDL) and low-density lipoprotein (LDL) were determined using commercial kits (Dia lab, Austria). The tissues were then homogenized in Tris- $\mathrm{HCl}$ buffer, $0.1 \mathrm{M}$ pH 7.4. 
The homogenate was used for the assay of tissue glycogen content, ${ }^{15}$ ) plasma enzymes like alanine aminotransferase (ALT), aspartate aminotransferase (AST),${ }^{16)}$ alkaline phosphatase (ALP), ${ }^{17)}$ and acid phosphatase (ACP). ${ }^{18)}$

Statistical Analysis — Statistical analysis was performed using SPSS software version 14.0. The values were analyzed with one-way analysis of variance (ANOVA), followed by Duncan's multiplerange test (DMRT). ${ }^{19)}$ All results are expressed as mean \pm S.D. for 6 rats in each group. $P$ values of less than 0.05 were considered to represent statistically significant difference.

\section{RESULTS}

Plasma glucose levels measured in normal and experimental rats at the end of 15, 30, and 60 days of treatment are given in Table 1. STZ-induced diabetic rats showed a significant increase in the blood glucose levels as compared with normal rats. Oral administration of the hexane extract showed a significantly $(p<0.05)$ greater effect than the ethyl acetate and methanol crude extracts.

Table 2 presents the effects of the hexane extract on change in body weight, $\mathrm{HbA}_{1 \mathrm{c}}$, liver and muscle glycogen, and plasma insulin in normal and diabetic rats. In diabetic rats, there was a significant $(p<0.05)$ decrease in body weight, tissue glycogen, and plasma insulin and an increase in $\mathrm{HbA}_{1 \mathrm{c}}$ compared with normal rats. Oral administration of the hexane extract significantly $(p<0.05)$ increased the body weight, tissue glycogen, and plasma insulin and decreased $\mathrm{HbA}_{1 \mathrm{c}}$ when compared with untreated diabetic rats.

Table 3 shows the levels of urea, uric acid, creatinine, protein, serum lipids and plasma enzymes like AST, ALT, ALP, and ACP in normal and diabetic rats. There was a significant increase in urea, uric acid, creatinine, total cholesterol, and plasma enzymes and decreased level of protein and

Table 1. Effects of C. speciosus Crude Extracts on Plasma Glucose Levels in Normal and Streptozotocin-Induced Diabetic Male Wistar Rats after 60 Days of Treatment

\begin{tabular}{|c|c|c|c|c|c|}
\hline \multirow{3}{*}{$\begin{array}{l}\text { Group } \\
\text { Normal + CMC }\end{array}$} & \multicolumn{5}{|c|}{ Plasma glucose level (mg/dl) } \\
\hline & Day 0 & Day 15 & \multicolumn{2}{|c|}{ Day 30} & Day 60 \\
\hline & $81.25 \pm 8.2$ & $79.14 \pm 7.41^{a}$ & $78.60 \pm$ & $8.31^{a}$ & $76.08 \pm 9.61^{a}$ \\
\hline Nornal + glibenclamide & $74.66 \pm 5.75$ & $75.56 \pm 6.80^{a}$ & $80.80 \pm$ & $8.10^{a}$ & $79.47 \pm 7.24^{a}$ \\
\hline Normal + hexane & $73.66 \pm 7.11$ & $79.24 \pm 7.22^{a}$ & $77.95 \pm$ & $3.50^{a}$ & $75.11 \pm 9.16^{a}$ \\
\hline Normal + ethyl acetate & $78.26 \pm 8.68$ & $80.81 \pm 8.30^{a}$ & $84.75 \pm$ & $6.04^{a}$ & $81.80 \pm 8.68^{a}$ \\
\hline Normal + methanol & $80.28 \pm 6.09$ & $78.28 \pm 8.60^{a}$ & $75.49 \pm$ & $4.36^{a}$ & $78.04 \pm 4.81^{a}$ \\
\hline Diabetic + CMC & $341.41 \pm 25.34$ & $369.07 \pm 11^{e}$ & $420.07 \pm$ & $20.86^{e}$ & $443.06 \pm 14.72^{e}$ \\
\hline Diabetic + glibenclamide & $350.63 \pm 21.77$ & $238.76 \pm 14.32^{b, c}$ & $155.15 \pm$ & $19.08^{b}$ & $121.78 \pm 7.32^{b}$ \\
\hline Diabetic + hexane & $347.60 \pm 24.10$ & $232.69 \pm 16.06^{b}$ & $182.11 \pm$ & $12.74^{c}$ & $132.29 \pm 7.53^{b, c}$ \\
\hline Diabetic + ethyl acetate & $338.68 \pm 19.99$ & $279.63 \pm 9.54^{d}$ & $228.23 \pm$ & $11.78^{d}$ & $164.29 \pm 13.11^{d}$ \\
\hline Diabetic + methanol & $346.08 \pm 20.56$ & $249.26 \pm 12.58^{c}$ & $193.85 \pm$ & 11.16 & $143.15 \pm 17.58^{c}$ \\
\hline
\end{tabular}

Each value is $\pm \mathrm{SD}$ for six rats in each group. Values not sharing a common superscript differ significantly at $p<0.05$ (DMRT). Superscript "a" significantly differ from "b" and "c" is significantly differ from a adn b. Superscript "d" significantly differ from a, b and c like this. Same superscript means they are not significantly differ from each other.

Table 2. Effects of C. speciosus Crude Extracts on Body Weight, Glycosylated Hemoglobin, Muscle and Liver Glycogen, and Plasma Insulin Levels in Normal and Streptozotocin-Induced Diabetic Male Wistar Rats after 60 Days of Treatment

\begin{tabular}{|c|c|c|c|c|c|c|}
\hline \multirow[t]{2}{*}{ Group } & \multicolumn{2}{|c|}{ Body weight (g/day) } & \multirow{2}{*}{$\begin{array}{c}\text { Glycosylated } \\
\text { hemoglobin } \\
(\% \text { of total } \mathrm{Hb})\end{array}$} & \multirow{2}{*}{$\begin{array}{c}\text { Muscle } \\
\text { glycogen } \\
\text { (g/100 g wet } \\
\text { tissue) }\end{array}$} & \multirow{2}{*}{$\begin{array}{c}\text { Liver } \\
\text { glycogen } \\
\text { (g/100 g wet } \\
\text { tissue) }\end{array}$} & \multirow{2}{*}{$\begin{array}{l}\text { Plasma } \\
\text { insulin } \\
(\mu \mathrm{U} / \mathrm{ml})\end{array}$} \\
\hline & Initial & Final & & & & \\
\hline Normal + CMC & $203.9 \pm 8.3$ & $214.2 \pm 8.4^{c}$ & $0.49 \pm 0.03^{a}$ & $9.50 \pm 0.78^{b, c}$ & $48.40 \pm 2.85^{c, d}$ & $15.85 \pm 1.82^{c}$ \\
\hline Nornal + glibenclamide & $202.9 \pm 7.1$ & $211.4 \pm 7.0^{c}$ & $0.52 \pm 0.02^{a, b}$ & $9.27 \pm 1.30^{b, c}$ & $47.64 \pm 2.60^{c}$ & $13.64 \pm 1.63^{b, c}$ \\
\hline Normal + hexane & $206.0 \pm 9.1$ & $218.4 \pm 6.9^{c}$ & $0.50 \pm 0.02^{a}$ & $10.24 \pm 1.42^{c}$ & $51.55 \pm 2.82^{d}$ & $15.35 \pm 2.17^{b, c}$ \\
\hline Diabetic + CMC & $204.2 \pm 7.2$ & $183.2 \pm 7.3^{a}$ & $0.86 \pm 0.07^{c}$ & $2.33 \pm 0.77^{a}$ & $19.05 \pm 2.09^{a}$ & $5.69 \pm 1.22^{a}$ \\
\hline Diabetic + glibenclamide & $200.3 \pm 9.5$ & $201.1 \pm 7.0^{b}$ & $0.47 \pm 0.03^{a}$ & $9.33 \pm 1.18^{b, c}$ & $46.73 \pm 3.39^{c}$ & $14.88 \pm 1.88^{b, c}$ \\
\hline Diabetic + hexane & $210.4 \pm 6.8$ & $212.6 \pm 9.9^{c}$ & $0.57 \pm 0.07^{a}$ & $8.44 \pm 0.73^{b}$ & $43.11 \pm 3.10^{b}$ & $13.46 \pm 1.49^{b}$ \\
\hline
\end{tabular}

Each value is \pm SD for six rats in each group. Values not sharing a common superscript differ significantly at $p<0.05$ (DMRT). Superscript "a" significantly differ from "b" and "c" is significantly differ from a adn b. Superscript "d" significantly differ from a, b and c like this. Same superscript means they are not significantly differ from each other. 
Table 3. Effects of C. speciosus Crude Extracts on Serum Urea, Uric Acid, Creatinine, Protein, Total Cholesterol, Triglycerides, HDL, LDL, and Plasma AST, ALT, ACP, and ALP in Normal and Streptozotocin-Induced Diabetic Male Wistar Rats after 60 Days of Treatment

\begin{tabular}{|c|c|c|c|c|c|c|}
\hline \multirow[t]{2}{*}{ Parameter } & \multicolumn{6}{|c|}{ Groups } \\
\hline & $\begin{array}{c}\text { Normal + } \\
\text { CMC }\end{array}$ & $\begin{array}{c}\text { Nornal + } \\
\text { glibenclamide }\end{array}$ & $\begin{array}{c}\text { Normal + } \\
\text { hexane }\end{array}$ & $\begin{array}{c}\text { Diabetic + } \\
\text { CMC }\end{array}$ & $\begin{array}{c}\text { Diabetic + } \\
\text { glibenclamide }\end{array}$ & $\begin{array}{c}\text { Diabetic + } \\
\text { hexane }\end{array}$ \\
\hline Urea (mg/dl) & $21.90 \pm 2.27^{b}$ & $19.21 \pm 1.96^{a}$ & $18.58 \pm 1.21^{a}$ & $36.77 \pm 2.67^{c}$ & $21.76 \pm 2.04^{b}$ & $23.28 \pm 2.14^{b}$ \\
\hline Uric acid (mg/dl) & $1.18 \pm 0.147^{a}$ & $1.10 \pm 0.03^{a}$ & $1.09 \pm 0.06^{a}$ & $1.90 \pm 0.14^{c}$ & $1.13 \pm 0.07^{a}$ & $1.36 \pm 0.10^{b}$ \\
\hline Creatinine $(\mathrm{mg} / \mathrm{dl})$ & $1.02 \pm 0.11^{a, b}$ & $1.06 \pm 0.08^{a, b}$ & $0.98 \pm 0.08^{a}$ & $2.10 \pm 0.14^{c}$ & $1.10 \pm 0.15^{a, b}$ & $1.22 \pm 0.19^{b}$ \\
\hline Protein $(\mathrm{g} / \mathrm{dl})$ & $8.63 \pm 0.58^{b}$ & $8.22 \pm 0.33^{b}$ & $8.05 \pm 0.06^{b}$ & $3.36 \pm 0.58^{a}$ & $8.46 \pm 0.78^{b}$ & $8.04 \pm 0.50^{b}$ \\
\hline Total cholesterol (mg/dl) & $92.28 \pm 2.06^{a}$ & $93.66 \pm 2.25^{a}$ & $92.87 \pm 2.11^{a}$ & $241.33 \pm 8.12^{c}$ & $111.70 \pm 7.09^{b}$ & $106.31 \pm 5.39^{b}$ \\
\hline Triglycerides (mg/dl) & $16.33 \pm 1.86^{a, b}$ & $14.33 \pm 1.61^{a}$ & $15.04 \pm 1.99^{a}$ & $41.77 \pm 3.49^{c}$ & $16.63 \pm 2.28^{a, b}$ & $18.06 \pm 2.12^{b}$ \\
\hline HDL (mg/dl) & $55.90 \pm 2.94^{c}$ & $52.55 \pm 1.84^{b, c}$ & $54.45 \pm 3.42^{b, c}$ & $31.31 \pm 3.75^{a}$ & $53.02 \pm 3.78^{b, c}$ & $51.25 \pm 3.51^{b}$ \\
\hline $\mathrm{LDL}(\mathrm{mg} / \mathrm{dl})$ & $82.00 \pm 2.26^{a}$ & $80.56 \pm 2.38^{a}$ & $81.35 \pm 1.42^{a}$ & $146.59 \pm 3.54^{c}$ & $87.36 \pm 4.98^{b}$ & $91.32 \pm 4.86^{b}$ \\
\hline AST (U/dl) & $34.69 \pm 3.03^{a}$ & $36.33 \pm 2.22^{a}$ & $33.70 \pm 2.31^{a}$ & $65.49 \pm 3.59^{c}$ & $40.92 \pm 3.54^{b}$ & $42.17 \pm 3.17^{b}$ \\
\hline $\operatorname{ALT}(\mathrm{U} / \mathrm{dl})$ & $52.43 \pm 4.65^{a}$ & $51.81 \pm 2.46^{a}$ & $50.90 \pm 1.64^{a}$ & $88.82 \pm 5.42^{b}$ & $56.91 \pm 5.32^{a}$ & $55.29 \pm 6.39^{a}$ \\
\hline $\mathrm{ACP}(\mathrm{U} / \mathrm{dl})$ & $49.89 \pm 4.33^{a}$ & $48.42 \pm 3.03^{a}$ & $51.54 \pm 2.63^{a}$ & $85.20 \pm 3.49^{c}$ & $52.43 \pm 4.84^{a}$ & $57.69 \pm 4.18^{b}$ \\
\hline $\operatorname{ALP}(\mathrm{U} / \mathrm{dl})$ & $11.12 \pm 2.19^{a}$ & $11.62 \pm 2.07^{a}$ & $10.54 \pm 1.12^{a}$ & $23.00 \pm 2.83^{c}$ & $13.85 \pm 1.98^{a}$ & $14.37 \pm 2.42^{b}$ \\
\hline
\end{tabular}

Each value is \pm SD for six rats in each group. Values not sharing a common superscript differ significantly at $p<0.05$ (DMRT). Superscript "a" significantly differ from "b" and "c" is significantly differ from a adn b. Superscript "d" significantly differ from a, b and c like this. Same superscript means they are not significantly differ from each other.

HDL cholesterol in diabetic rats compared with normal rats. C. speciosus hexane extract treatment for 60 days restored these parameters to nearly normal in diabetic rats.

\section{DISCUSSION}

Diabetes mellitus of long duration is associated with several complications such as atherosclerosis, myocardial infarction, neuropathy, nephropathy, etc. These complications have long been assumed to be related to chronically elevated blood glucose levels. Diabetes mellitus causes disturbances in the uptake of glucose as well as glucose metabolism. After treatment with low doses of STZ there should be many surviving $\beta$-cells, and regeneration is also possible. ${ }^{20)}$

Increased levels of plasma glucose in STZinduced diabetic rats were lowered by the administration of $C$. speciosus crude extracts. The hypoglycemic effects of $C$. speciosus may result from the potentiation of insulin from existing $\beta$-cells of the islets of Langerhans. The plasma glucose-lowering effect was compared with glibenclamide, a standard hypoglycemic drug. Glibenclamide has been used for many years to treat diabetes and stimulates insulin secretion from pancreatic $\beta$-cells. ${ }^{21)}$ The decrease in body weight of diabetic rats is possibly due to decreased catabolism of fats and protein content in muscle tissue by proteolysis. ${ }^{22)}$ Oral administration of the $C$. speciosus hexane extract partially improved body weight in diabetic rats. $\mathrm{HbA}_{1 \mathrm{c}}$ is produced through the glycosylation of hemoglobin, is formed progressively and irreversibly over time, is stable throughout the life of red blood cells and is unaffected by diet, insulin or exercise on the day of testing. ${ }^{23-25)}$ In this study a significant decrease in $\mathrm{HbA}_{1 \mathrm{c}}$ occurred in diabetic rats after treatment with the $C$. speciosus hexane crude extract. This indicates that overall blood glucose control is improved due to improvement in insulin secretion.

The decreased level of tissue glycogen in diabetic rats is probably due to the lack of insulin in the diabetic state which results in the inactivation of the glycogen synthetase system. ${ }^{26)}$ Administration of $C$. speciosus crude extracts increases the skeletal muscle and liver glycogen content. Thus prevention of glycogen depletion in the liver and muscle might possibly be due to stimulation of insulin release from $\beta$-cells, which in turn reactivate the glycogen synthetase system. These results are in aggrement with those in other studies on Eugenia jambolana, which prevented the depletion in the liver and skeletal muscle glycogen content in alloxan-induced diabetic rabbits. $^{8)}$

The plasma insulin level decreases in diabetic animals. The serum insulin level was increased in diabetic rats administered Gymnema sylvestre ( $G$. sylvestre) suggesting the insulinotropic activity of G. sylvestre leaf extract. ${ }^{27,28)}$ This result agrees well with those of the present study, when the plasma insulin level of diabetic animals treated with $C$. speciosus hexane extract increased compared with 
the diabetic controls.

Hyperglycemia induces elevation of the serum levels of urea, uric acid and creatinine leading to renal dysfunction. ${ }^{29)}$ In the present study there was a significant $(p<0.05)$ increase in the levels of serum urea, uric acid, and creatinine in diabetic rats when compared with control rats. When diabetic rats received the hexane crude extract, the levels of urea, uric acid and creatinine were significantly $(p<0.05)$ decreased. This result coincides with the previous studies on the mesocarp extract of Balanites aegyptiaca ${ }^{30,31)}$ and the root extract of Panax ginseng. ${ }^{32)}$ A marked $(p<0.05)$ reduction in plasma total protein level was observed in diabetic rats due to increased protein catabolism. ${ }^{30)}$ The present study found that the administration of the $C$. speciosus hexane crude extract increased the total protein as compared with normal levels.

The increase in the levels of plasma AST, ACT, ALP, and ACP indicated that diabetes may be induced due to liver dysfunction. It was also reported that the liver was necrotized in STZ-induced diabetic rats. ${ }^{33)}$ Therefore the increase in the levels of AST, ALT, ALP, and ACP in plasma may be mainly due to the leakage of these enzymes from the liver cytosol into the blood stream, ${ }^{34)}$ which indicates on the hepatotoxic effects of STZ. Oral administration of the $C$. speciosus hexane extract resulted in near normalization of plasma AST, ALT, ALP, and ACP. This extract may alleviate the liver damage caused by STZ-induced diabetes.

High levels of total cholesterol and more importantly LDL cholesterol in the blood are major coronary risk factors. ${ }^{35)}$ The abnormaly high concentration of serum lipids in the diabetic is due mainly to the increase in the mobilization of free fatty acids from the peripheral fat depots, since insulin inhibits hormone sensitive lipase. Insulin deficiency or insulin resistance may be responsible for dyslipidemia, because insulin has an inhibitory action on 3-hydroxy-3-methylglutaryl coenzyme A (HMGcoA) reductase, a key rate-limiting enzyme responsible for the metabolism of cholesterol-rich LDL particles. Acute insulin deficiency initially causes an increase in free fatty acid mobilization from adipose tissue. This results in increased production of cholesterol-rich LDL particles. ${ }^{36-38)} \mathrm{HDL}$ is an antiatherogenic lipoprotein. It transports cholesterol from peripheral tissue into the liver and thereby acts as a protective factor against coronary heart disease. The level of HDL cholesterol, which increased after hexane extract administration, might be due to the increase in the activity of lecithin cholesterol acyl transferase, which may contribute to the regulation of blood lipids. ${ }^{39)}$ Oral administration of C. speciosus crude extracts lowered serum lipids and LDL cholesterol level in diabetic rats.

We conclude that the hexane crude extract of C. speciosus rhizome was effective in decreasing the serum glucose level and normalizing the other biochemical parameters in diabetic rats. The hexane extract was more potent than the ethyl acetate and methanol extracts. The evidences suggest that rhizome of $C$. speciosus could be beneficial for the protection and alleviation of diabetic complications. Further studies need to be carried out to define the active principle(s) present in the hexane crude extract.

Acknowledgement This study was financially supported by the University Grants Commission (F. No. 32-505/2006 SR), New Delhi, India.

\section{REFERENCES}

1) Kim, S. H., Hyun, S. H. and Choung, S. Y. (2006) Anti-diabetic effect of cinnamon extract on blood glucose in db/db mice. J. Ethnopharmacol., 104, 119-123.

2) Lopez-Candales, A. (2001) Metabolic syndrome $X$ : a comprehensive review of the pathophysiology and recommended therapy. J. Med., 32, 283-300.

3) Verspohl, E. J. (2002) Recommended testing in diabetes research. Planta Med., 68, 581-590.

4) De Sousa, E., Zanatta, L., Seifriz, I., Creczynski-Pasa, T. B., Pizzolatti, M. G., Szpoganicz, B. and Silva, F. R. M. B. (2004) Hypoglycemic effect and antioxidant potential of kaempferol 3,7-O $(\alpha)$ dirhamnoside from Bauhinia forficate leaves. J. Nat. Prod., 67, 829-832.

5) Colca, J. R. (2006) Insulin sensitizer may prevent metabolic inflammation. Biochem. Pharmacol., 72, 125-131.

6) Valiathan, M. S. (1998) Healing plants. Current Science, India, 75, 1122-1126.

7) Wang, H. X. and Ng, T. B. (1999) National products with hypoglycemic, hypotensive, hypocholesterolemic, antiatherosclerotic andantithrombotic activities. Life Sci., 65, 2663-2677.

8) Sharma, S. B., Nasir, A., Prabhu, K. M., Murthy, P. S. and Dev, G. (2003) Hypoglycemic and hypolipidemic effect of ethanolic extract of seeds of 
Eugenia jambolana in alloxan-induced diabetic rabbits. J. Ethnopharmacol., 85, 201-206.

9) Battacharya, S. K., Parik, A. K., Debnath, P. K., Pandey, V. B. and Neogy, N. C. (1972) Anticholiesterase activity of Costus speciosus alkaloids. Indian J. Pharmacol., 4, 178-179.

10) Mosihuzzaman, M., Nahar, N., Alic Kokeya, B., Khan, A. K., Nur-E-Alam, M. and Nandi, R. P. (1994) Hypoglycemic effects of three plants from eastern himalayan belt. Diabetes research, 26, 127138.

11) Trinder, P. (1969) Determination of glucose in blood using glucose oxidase with an alternative oxygen acceptor. Ann. Clin. Biochem., 6, 24-27.

12) Lowry, O. H., Rosenbrough, N. J., Farr, A. L. I. and Randall, R. L. (1951) Protein measurement with the Folin-Phenol reagent. J. Biol. Chem., 193, 264-275.

13) Sudhakar Nayak, S. and Pattabiraman, T. N. (1981) A new colorimetric method for common haemoglobin. CLINICA CHIMICA ACTA, 109, 267-274.

14) Bannon, P. (1982) Effect of $\mathrm{pH}$ on the estimation of the labile fraction of glycosylated hemoglobin. Clin. Chem., 28, 2183.

15) Morales, M. A., Jabbagy, A. J. and Terenizi, H. R. (1973) Mutations affecting accumulation of glycogen. Neurospora News, 20-24.

16) Reitman, S. and Frankel, S. A. (1957) Colorimetric method for the determination of serum glutamic oxaloacetic and glutamic pyruvic transaminases. Am. J. Clin. Pathol., 28, 56-63.

17) Principato, G. B., Asia, M. C., Talesa, V., Rosi, G. and Giovannini, E. (1985) Characterization of the soluble alkaline phosphatase from hepatopancreas of Squilla mantis L. Comp. Biochem. Physiol. B., 80, 801-804.

18) Moss, D. W. (1984) In Methods of enzymatic Analysis, Vol.4, third ed. (Bergmeyer, H. U., Ed.), verlagchemic, Berlin, pp. 92-106.

19) Duncan, B. D. (1957) Multiple range test for correlated and heteroscedastic means. Biometrics, 13, 359-364.

20) Gomes, A., Vedasiromoni, J. R., Das, M., Sharma, R. M. and Ganguly, D. K. (2001) Antihyperglycemic effect of black tea (Camellia sinensis) in rat. J. Ethnopharmacol., 27, 243-275.

21) Tian, Y. M., Johnson, G. and Ashcroft, J. H. (1998) Sulfonylureas enhance exocytosis from pancreatic $\beta$-cells by a mechanism that does not involve direct activation of protein kinase C. Diabetes, 47, 17221726.

22) Vats, V., Yadav, S. P. and Grover, J. K. (2004) Ethanolic extract of Ocimum sanctum leaves par- tially attenuates streptozotocin induced alterations in glycogen content and carbohydrate metabolism in rats. J. Ethnopharmacol., 90, 155-160.

23) Bunn, H. F., Haney, D. N., Kamin, S., Gabby, K. H. and Gallop, P. M. (1976) The biosynthesis of human hemoglobin $\mathrm{A}_{1 \mathrm{C}}$. J. Clin. Invest., 57, 1652-1659.

24) Bunn, H. F., Gabby, K. H. and Gallop, P. M. (1978) The glycosylation of hemoglobin relevance to diabetes mellitus. Science, 200, 21-27.

25) Bunn, H. F. (1981) Evaluation of glycosylated hemoglobin in diabetic patients. Diabetes, 30, 613.

26) Perfumi, M., Arnold, N. and Tacconi, R. (1991) Hypoglycemic activity of Salvia fruticosa Mll from Cyprus. J. Ethnopharmacol., 34, 135-140.

27) Shanmugasundaram, K. R., Paneerselvam, C., Samudram, P. and Shunmugasundaram, E. R. B. (1981) The insulinotropic activity of Gymnema sylvestre $\mathrm{R}$. Br. an Indian medical herb used in controlling diabetes mellitus. Pharmacol. Res., 13, 475486.

28) Shumugasundaram, K. R., Paneerselvam, C., Samudram, P. and Shunmugasundaram, E. R. B. (1983) Enzyme changes and glucose utilization in diabetic rabbits, the effect of Gymnema sylvestre. J. Ethnopharmacol., 7, 205-234.

29) Almdal, J. P. and Vilstrup, H. (1988) Strict insulin therapy normalizes organ nitrogen contents and the capacity of urea nitrogen synthesis in experimental diabetes in rats. Diabetologia, 31, 114-118.

30) Mansour, H. A. and Newairy, A. A. (2000) Amelioration of impaired renal function associated with diabetes by Balanites aegyptiaca fruits in streptozotocin induced diabetic rats. Journal of the Medical Research Institute, 21, 115-125.

31) Saeed, A., Ibrahim, N., Bashandy, S. and El-Gengaihi, S. (1995) Saponin of Balanites aegyptiaca Del fruits and biological evaluation. Bulletin of the Faculty of Pharmacy, 33, 105.

32) Badr El-Din, N. K. (1997) Effect of Panax ginseng extract on the nephrotoxicity of streptozotocin induced experimental diabetes. Egyptian Journal of Biochemistry, 15, 29-52.

33) Ohaeri, O. C. (2001) Effect of garlic oil on the levels of various enzymes in the serum and tissue of streptozotocin diabetic rats. Bioscience reports., 21, 19-24.

34) Navarro, C. M., Montilla, P. M., Martin, A., Jimenez, J. and Utrilla, P. M. (1993) Free radicals scavenger and antihepatotoxic activity of Rosmarinus. Planta Med., 59, 312-314.

35) Hannan, J. M. A., Rokeya, B., Faruque, O., Nahar, N., Mosihuzzaman, M., Khan, A. K. A. and Ali, L. (2003) Effect of soluble dietary fibre fraction 
of Trigonella foenum graecum on glycemic, insulinemic, lipedimic and platelet aggregation status of type 2 diabetic model rats. J. Ethnopharmacol., 88, 73-77.

36) Balasee, E. O., Bier, D. M. and Havel, R. J. (1972) Early effects of anti insulin serum on hepatic metabolism of plasma free fatty acids in dogs. Diabetes, 21, 280-284.

37) Taskimen, M. R. (1987) Lipoprotein lipase in dia- betes. Diabetes Metab. Rev., 3, 551-570.

38) Murali, B., Upadhyaya, U. M. and Goyal, R. K. (2002) Effect of chronic treatment with Enicostemma litorale in non-insulin-dependent diabetic rats. J. Ethnopharmacol., 81, 199-204.

39) Patil, U. K., Saraf, S. and Dixit, V. K. (2004) Hypolipidemic activity of seeds of Cassia tora Linn. J. Ethnopharmacol., 90, 249-252. 